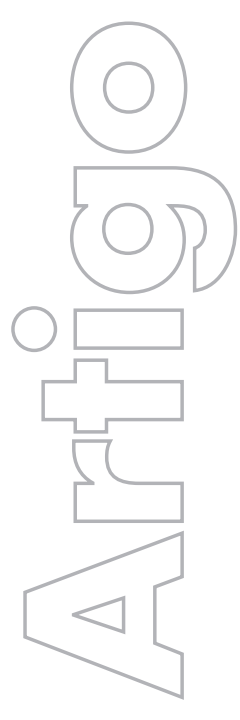

revista

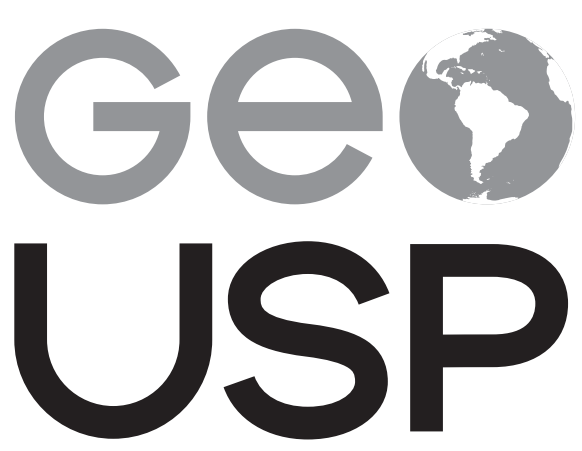

espaço e tempo

Volume $20 \cdot n^{\circ} 1(2016)$

\section{Memórias interioranas:} campo e cidade através do rádio numa comunidade ribeirinha amazônica

\author{
Catia Oliveira Macedo \\ UEPA; IFPA
}

Antonio Maurício Dias da Costa

UFPA

p. $130-141$

Como citar:

MACEDO, C. O.; COSTA, A. M. D. Memórias interioranas: campo e cidade através do rádio numa comunidade ribeirinha amazônica. Geousp - Espaço e Tempo (Online), v. 20, n. 1, p. 130-141, mês. 2016. ISSN 2179-0892.

Disponível em: http://www.revistas.usp.br/geousp/article/view/96986. DOI: http://dx.doi.org/10.11606/issn.21790892.geousp.2016.96986.

\section{(c) (i) (5)}

Este artigo está licenciado sob a Creative Commons Attribution 4.0 License. 


\title{
Memórias interioranas: campo e cidade através do rádio numa comunidade ribeirinha amazônica
}

\section{Resumo}

Os programas de rádio têm desempenhado um importante papel na comunicação entre os diversos pontos da região Amazônica desde a década de 1940. Na memória dos moradores mais antigos da comunidade da Foz do Cravo, localizada à margem do rio Bujaru, na Amazônia Oriental, a lembrança dos programas de rádio mobiliza representações acerca do modo de vida na cidade e no interior. Elas são elaboradas como referências simbólico-espaciais, engendradas a partir de experiências de recepção e interação com programas de rádio, muito ouvidos na região entre os anos de 1960 e 1980. Aqui, o levantamento preliminar das percepções socioespaciais sobre a Amazônia através de programas de rádio revela as formas de compreensão nativas da organização espacial vivida pelos sujeitos da memória.

Palavras-chave: Rádio. Amazônia. Cidade. Interior. Representações.

\section{Countryside Memories: town and country on the radio in an Amazonian riverine settlement}

\begin{abstract}
The radio programs have played an important role in the exchange of communication among different social spots in the Amazon during the 1940's. The memory of the elderly settlers from Foz do Cravo community, based on the margins of Bujaru River, eastern Amazon, refers to radio shows which prop up representations concerning life styles in the town and in the country. They are sketched as symbolic-spatial references, generated by experiences of reception and interaction with radio presentations, much appreciated in the settlement during the 1960's and the 1980's. The preliminary survey on social and spatial perceptions concerning the Amazon through radio broadcasting, as in this research, discloses examples of native comprehension of the spatial organization lived by the agents of memory.
\end{abstract}

Keywords: Radio. Amazon. Town. Countryside. Representations. 


\section{Introdução}

A divisão entre litoral e sertão sempre foi algo mais difícil de aplicar à Amazônia, quando comparada a outras regiões do território que viria historicamente a compor o Brasil. ${ }^{1}$ Os "litorais" amazônicos se estendem nas orlas de rios caudalosos e de igarapés. ${ }^{2}$ Os "sertões", entrecortados por várzeas, se espalham por diferentes configurações de relevo e de circuitos fluviais. Até os dias de hoje, rios, furos e igarapés recortam toda a região e são utilizados, de forma regular, como eficientes vias de transporte de pessoas, produtos e informações. No campo específico da comunicação, as extensões amazônicas podem tanto ser vistas, a partir da rede hidrográfica, como dotadas de vias de ligação ou como cortada por obstáculos às redes de rodovias, telefonia fixa e energia elétrica.

O rádio, por seu turno, tem sido um importante instrumento de conexão entre diferentes núcleos populacionais amazônicos desde o século XX até os dias de hoje. Mesmo em localidades sem energia elétrica, desde o aparecimento do "radinho de pilha", nos anos 1960, as notícias, músicas e mensagens ecoadas pelo rádio ajudavam os habitantes do interior da região a melhor avaliar sua relação com o espaço regional. Em outras palavras, o rádio tornou mais fácil, para essas populações, ampliar suas redes de troca, de comunicação e de trilhas de movimentação entre o espaço dos povoados, vilas, cidades pequenas, médias e grandes da Amazônia.

Neste artigo, tratamos de uma localidade em particular, um pequeno povoado conhecido como Foz do Cravo. Ainda nos tempos coloniais, a comunidade 3 ribeirinha foi formada a partir da ocupação entorno do médio rio Guamá e está localizada na foz do Igarapé Cravo, que corta a região entre os municípios de Bujaru e Concórdia do Pará, e desemboca no rio Bujaru. ${ }^{4}$ Sete famílias habitam atualmente a localidade e vivem de atividades como pesca, cultivo de roças de mandioca, da criação de gado, coleta de frutas e comércio.

1 Ao abordar uma reflexão proposta pelo historiador Sérgio Buarque de Holanda, Rafael Chambouleyron (2010, p. 18-19) afirma que a dicotomia sertão/litoral não é pertinente para compreender a ocupação histórica na Amazônia a partir da colonização portuguesa. Para ele, estes não constituíam universos distintos em termos socioespaciais. Tratouse o empreendimento de colonização de um "universo projetado de distintas formas sobre o imenso e heterogêneo território".

2 Trindade Jr. (2005, p. 194-199) destaca que a noção de orla na Amazônia inclui as margens dos rios e igarapés, que cortam as cidades e que servem como vias de transporte em trechos valorizados ou não do ambiente urbanístico.

3 Empregamos a expressão comunidade num sentido basicamente descritivo e como expressão "nativa", corrente entre moradores de localidades rurais amazônicas. Comunidade pode descrever tanto a proximidade de casas e a partilha da vida religiosa quanto os laços de parentesco entre moradores. Esses três aspectos se aplicam à comunidade da Foz do Cravo.

4 O surgimento da Foz do Cravo remonta ao processo de ocupação das margens do rio Bujaru, nos séculos XVIII e XIX, em particular, da povoação que originou a Freguesia de Santana, cujo papel foi fundamental na formação dos povoados instalados às margens do rio. Segundo Castro (2003, p. 74): "Os muitos igarapés que desembocam nesses rios integramse à rede hidrográfica e a ecossistemas ricos em biodiversidade, compostos de várzea e terra firme. Serviram no passado para ocupar terras interiores, levando a conformar lentamente um campesinato com roças de mandioca, milho e arroz, além de uma diversidade de plantas comestíveis - frutas, raízes e legumes - associadas a atividades extrativistas de drogas do sertão, madeira e posteriormente a borracha". 


\section{Mapa 1 - Localização da Comunidade da Foz do Cravo às margens do rio Bujaru. Destacam-se os municípios paraenses de Bujaru e Concórdia do Pará.}

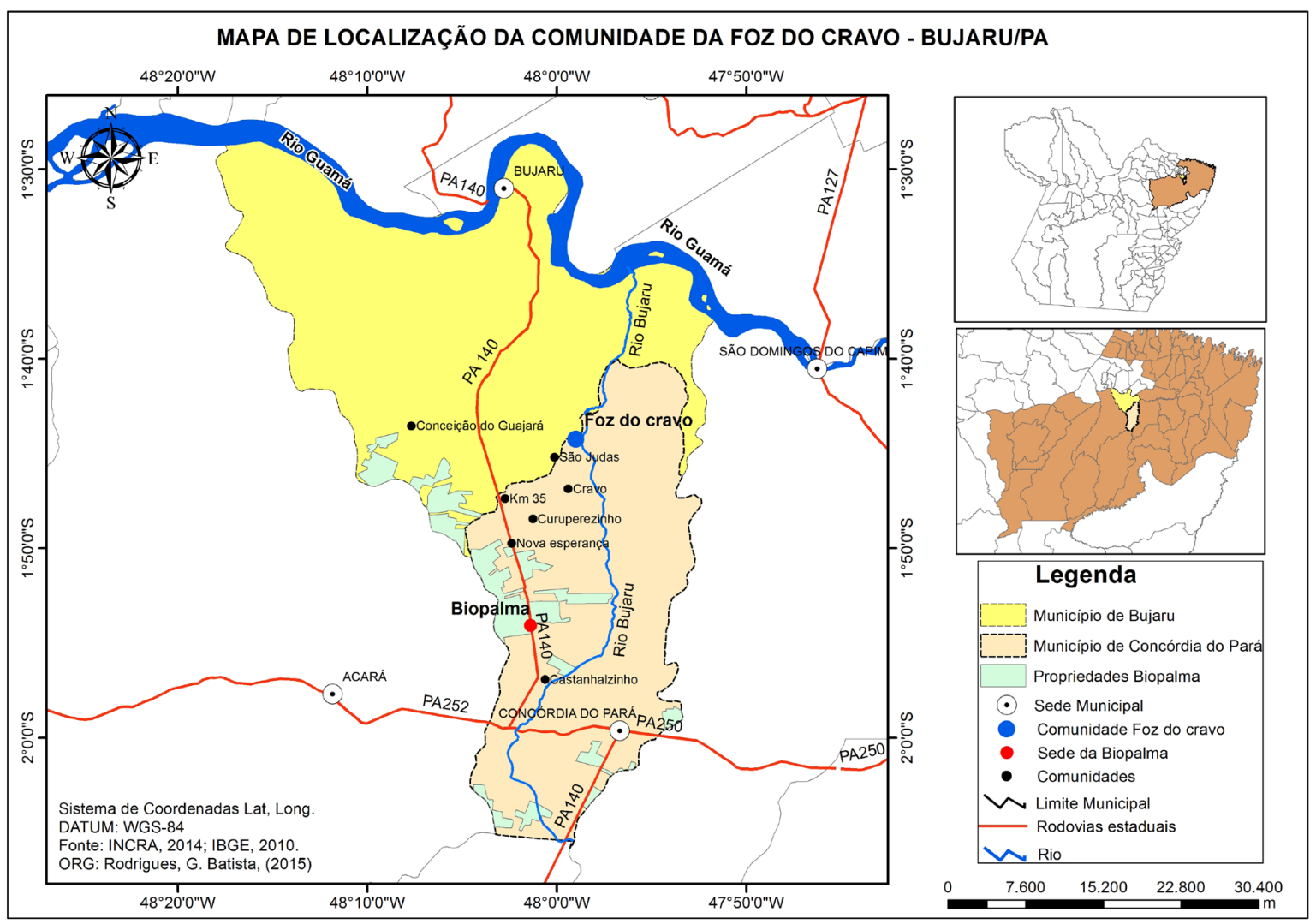

Segundo Edna Castro (2003, p. 153), a comunidade de Foz do Cravo mantém, ainda hoje, fortes vínculos com a Freguesia de Santana, povoação mais antiga da região. Esses vínculos se assentam nas "relações familiares, nas trocas econômicas, nas festividades e manifestações religiosas que thes garantem a unidade e a manutenção de um sistema de sociabilidade".

$\bigcirc$ foco do estudo são os relatos memorialísticos de alguns dos moradores mais antigos da comunidade e tratam do uso do rádio como um meio de intermediação entre o mundo rural e o urbano. Entendemos estes relatos como produção condicionada à realidade vivida no presente por estes sujeitos. Por isso, as referências memorialísticas são aqui analisadas como representações, isto é, como esboço mental, no qual se produz sentidos anunciados em discursos de iniciativa individual, mas balizados socialmente (Chartier, 1990, p. 17).

Por conta disso, a produção da memória implica num tipo de apropriação discursiva sobre o vivido, que acaba por interferir no presente. A produção de sentidos sobre a experiência pretérita implica num exercício de poder e sanciona a posição ocupada pelos sujeitos na sociedade do presente.

E o tema predominante desses relatos-representações é o de que o rádio intermediava o trânsito físico e comunicacional entre o campo e a cidade. $\bigcirc$ campo, aliás, é normalmente sinônimo de "interior" nas referências correntes de homens e mulheres da localidade consultados na pesquisa para indicar seu lugar de origem. 
Portanto, interior é uma categoria nativa, mas, ao mesmo tempo, um termo de uso comum em Belém e em outras cidades de médio e grande porte da Amazônia, para se referir aos espaços distantes da urbanização. É um termo também usado nos meios de comunicação, nos programas de emissoras locais de rádio, para se referir ao público de todo o estado: a população da cidade e do interior. Na fala dos comunicadores de massa, cidade e interior tendem a ser usados como antônimos, partes de uma totalidade que inclui as porções com maior ou menor intervenção antrópica na região.

\section{A Foz do Cravo entre o campo e a cidade}

Como outras populações "interioranas" da mesorregião do nordeste do Pará, a população de Foz do Cravo também contribuiu para o fluxo migratório de grande escala para a capital do estado entre os anos 1950 e 1980. Em estudo realizado na comunidade do Cravo, uma das vilas que compõem o conjunto de povoações ao longo do igarapé homônimo, Macedo (2011, p. 1-29) destaca a trajetória social dos camponeses dessa localidade marcada pela vivência entre o campo e a cidade.

Constatou-se nesta pesquisa que as décadas de 1970 e 1980 foram marcadas pela saída em massa desses trabalhadores em direção à cidade. Já a década de 1990 foi caracterizada pelo retorno de um número expressivo dessas familias. Isso se deveu às transformações ocorridas no campo brasileiro no limiar do século XX, por conta da melhoria de estradas, eletrificação rural, implantação da Educação Básica, bem como do sistema de comunicação via telefonia rural.

Na pesquisa, vislumbrou-se que o fluxo migratório se apresentou na região muito mais como um movimento de ir e vir, estabelecendo um contínuo de relações familiares, econômicas, de amizade e de partilha de informações. Isso pode ser constatado pelo uso feito, na localidade, das programações de rádio como um meio de entretenimento, de troca de mensagens e informação sobre a vida urbana.

Nossa análise segue o caminho inverso do que estipulavam os célebres estudos de comunidade desenvolvidos por sociólogos e antropólogos, brasileiros e estrangeiros, entre os anos 1950 e $1960^{5}$ sobre o modo de vida tradicional da população rural. A comunidade ribeirinha/ interiorana de Foz do Cravo não se desintegrou com a adoção de novos padrões de comportamento estipulados por novos meios de comunicação como o rádio.

Ao contrário, as ondas radiofônicas foram uma das pontes por onde se fez o trânsito e a comunicação entre campo e cidade. Esse fluxo engendrou certas representações sobre os espaços, que se vão construindo e reelaborando através do tempo. Daí que a aparente distância entre o modo de vida urbano e vida "típica" do interior se desfaz ao verificarmos o interesse dos ribeirinhos da Foz do Cravo pelos acontecimentos da capital, noticiados todos os dias em programas policiais, humorísticos e musicais. Essas informações eram úteis tanto para aqueles que seguiam na aventura de imigrar para a cidade como para os parentes que ficavam no interior e queriam saber das "novas" do dia a dia da capital. Serviam também para os que estavam frequentemente no trânsito cidade-interior, e utilizavam programas de rádio para enviar mensagens, como uma forma alternativa e altamente eficaz de "correio".

5 Entre as várias referências nesse campo, destacam-se algumas a título de exemplo: Willems e Mussolini (1952), Harris (1956), Wagley (1957), Willems (1961) e Antonio Cândido (1964). 
Assim, pode-se questionar a tese de que o sucesso da migração para as grandes cidades, por exemplo, se deveu à "falência de uma sociedade rural em desintegração". ${ }^{2}$ Da mesma forma, a leitura do campo centrada na expansão das relações capitalistas e do assalariamento não é suficiente para explicar a totalidade das transformações ocorridas no espaço rural contemporâneo. Pelo contrário, estas metamorfoses têm demonstrado que tanto a cidade quanto o campo apresentam novas dinâmicas sem, contudo, se desagregarem. A evidência da (re) construção permanente de territórios é demonstrada pela luta dos remanescentes de quilombos, dos sem-terra, dos atingidos por barragem e da inserção da pequena produção na política dos agrocombustíveis.

Ao longo da pesquisa, observamos que campo e cidade são reconstruídos simbolicamente com sentidos diversos nas falas dos que conheceram e participaram da experiência de migração e de trânsito entre Belém e o interior entre os anos de 1960 e 1970. Sentidos positivos e negativos, articulados tanto ao modo de vida "interiorano" quanto às repercussões sobre a vida urbana, se revelam na memória de ouvintes de programas de rádio de grande audiência no Pará do mesmo período.

É o que pode ser observado nas evocações memorialísticas de comerciantes, donas de casa e agricultores de Foz do Cravo, entrevistados por nós em dezembro de 2011. As seis pessoas com quem produzimos registros de história oral estão numa faixa etária entre 50 e 80 anos. Deduz-se, com isso, que o período mais ativo de registro memorial dos entrevistados se situa entre os anos de 1960 e 1980, por corresponder à fase entre a saída da infância e os primeiros anos da idade adulta. Aliás, foram encontradas várias pistas nas falas dos entrevistados que fazem referências às décadas assinaladas.

\section{Rádio e memórias na foz de um igarapé}

As memórias dos moradores da "Foz" destacam, em décadas passadas, a forte movimentação do "porto", local de embarque/desembarque de pessoas e produtos na confluência entre rio e igarapé. ${ }^{7}$ Recordam também os programas preferidos ouvidos no rádio e como era esse um elemento muito presente no cotidiano familiar. Radionovelas, programas de notícias policiais, informes de acontecimentos de vulto, entre outros, apresentavam a cidade numa relação de confluência com a população do interior. ${ }^{8}$

6 Representativo dessa perspectiva é o clássico estudo de Eunice Durham (1978) sobre o fenômeno da migração rural em massa para São Paulo nas décadas de 1960 e 1970.

7 Com base em Macedo (2011), destacamos a importância da Foz do Cravo para o transporte de pessoas e mercadoria na região nos anos de 1960 e 1970. É o que aponta a fala de Noé Eugênio Macedo, 76 anos, agricultor aposentado e morador da vila do Cravo: "A viagem até a Foz do Cravo era difícil. Nós saíamos de madrugada com chuva e, nesse tempo era tudo mais difícil. Quando o tempo 'tava ruim, a gente encontrava com árvore no meio do igarapé. Caia árvore. Aí, a gente tinha que descer da canoa tirar a árvore do meio do igarapé e continuar. Eram horas e horas trabalhando pesado p'ra canoa poder passar. A gente viajava molhado durante muito tempo. Não sei como não adoecia. Sempre tinha uma pinga e um porronquinha p'ra esquentar. E o barco cheio de farinha. Quando o tempo 'tava muito ruim, chegamos a perder a mercadoria. No início do ano, era chuva na ida e chuva na volta. Era cada tempestade que a gente pensava que o mundo ia acabar. [...] Hoje, a gente anda de ônibus; pega o ônibus na porta de casa. Se um mais novo precisar fazer uma viagem de barco, ele não sabe fazer. A gente sabia tudo, tinha os momentos de descontração, tinha as nossas brincadeiras, os mais jovens até namoravam" (Entrevista feita na Comunidade do Cravo, em fevereiro de 2010).

8 Isso vai além do argumento de autores como Rocha (2007, p. 44) e Tinhorão (1981, p. 73), que afirmam ter sido o rádio, nos anos 1940 e 1950, veiculador do fascínio das populações interioranas do Brasil pelas "maravilhas" dos grandes centros urbanos. 
$\bigcirc$ registro individual de imagens e acontecimentos relatados pelos entrevistados está pautado na experiência coletiva dos ouvintes de rádio da comunidade, que experimentavam periodicamente idas e vindas da capital. Trata-se de uma memória individual e, ao mesmo tempo, informada pelo que foi vivido com os outros e pelo ouvir dizer. Mais do que isso, memória construída na interação coletiva e equacionada pela relação com o espaço. É o que propõe Halbwachs (2006, p. 73-74), ao afirmar que nossas impressões sobre os acontecimentos são por nós inscritas "no ambiente natural que nos circunda". Memórias apoiadas em evidências espaciais de igarapés, rios, caminhos, vilas e cidades estão presentes nas falas dos entrevistados. A memória dos programas veiculados pelas ondas do rádio tem o pano de fundo espacial, vivenciado pelos sujeitos no ambiente familiar, nas atividades de trabalho, nas viagens, na alternância entre ambientes urbanos e rurais.

A peculiaridade da evocação memorialística dos moradores da Foz deve-se, certamente às condições locais de convivência coletiva no passado e no presente. Esse processo, no entanto, deve ser entendido como a extração de registros individuais, particulares, do que foi experimentado e partilhado coletivamente. Os entrevistados falam por si. Concordamos com Portelli (2006, p. 127), para quem "a memória só se materializa nas reminiscências e nos discursos individuais".

Por isso é que, de acordo com o perfil atual das populações regionais, a configuração de sua memória coletiva sobre os meios de comunicação na Amazônia ocorre de diferentes formas em diferentes contextos. Os idosos de Foz do Cravo recordam uma realidade anterior bastante diversa da atual, em que as estradas desempenham cada vez mais o papel exercido pelos rios. Suas memórias se articulam de forma imperfeita, expressando algumas diferenças entre versões coletivas e individuais. Assim é que as memórias individuais se casam ao acervo coletivo e acompanham as transformações socioeconômicas vividas na comunidade nas últimas décadas.

Ao longo desse período, ocorreu um evidente crescimento e maior dinamismo econômico em localidades adjacentes ou situadas à margem da rodovia mais próxima, a PA 140, aberta nos anos 1970, mas só asfaltada na década de 1990. É o caso da Comunidade do Cravo, que gradualmente se tornou o polo de convergência, com relação às comunidades vizinhas. $A$ intensificação do uso do transporte terrestre provocou uma centralização de atividades (lazer, religiosas e econômicas) na vila, tornada importante ponto de ligação das vilas rurais com a estrada e as cidades mais próximas (Macedo, 2011). Em contrapartida, a Foz, nos dias de hoje, é lugar de pouco movimento de viajantes e mercadorias. Aliás, a comunidade é composta por pequeno número de famílias, vinculadas à localidade por laços de parentesco e por atividades econômicas de pequena escala.

Tal condição, no entanto, não sugere desagregação social ou decadência econômica. Temos, na verdade, uma comunidade "envelhecida", mas que hoje desempenha um papel complementar, em termos socioespaciais, a fazendas, a outras comunidades rurais mais povoadas e ao grande projeto de produção de biodiesel, a partir do óleo de dendê da empresa Biovale. ${ }^{9}$

9 Biovale é o consórcio das empresas Vale S.A. e Biopalma. No estado do Pará, dedica-se à atividade produtiva em torno da cadeia do biodiesel. 
Com o início das atividades da Biovale no município de Concórdia do Pará em 2008, Foz do Cravo, assim como as demais comunidades adjacentes, tornaram-se área de pretensão da empresa, quer seja, pela potencialidade de mão de obra, de terras passíveis de negociação ou pela possibilidade de inserção de pequenas propriedades na cadeia produtiva do agro combustível. Com a iniciativa da Biovale de construir aproximadamente $20 \mathrm{~km}$ de uma estrada vicinal, ligando Foz do Cravo à PA-140, a comunidade reorientou o transporte de pessoas e mercadorias para a rodovia. Mudava, assim, um padrão de dependência quase exclusiva dos rios, que se manteve até fins do século XX. $\bigcirc$ recém-aberto ramal, como é conhecido esse tipo de estrada vicinal na região, serviria para garantir, principalmente, o trânsito de ônibus e caminhões, veículos utilizados no deslocamento de empregados na empresa moradores da área.

Tanto em termos espaciais como socioeconômicos, a comunidade de Foz do Cravo exerce hoje um papel intermediário entre a vida ribeirinha e os assentamentos ligados ao eixo rodoviário da região. Isso certamente intensificou ainda mais as trocas e a comunicação com a vida urbana pelos moradores da comunidade. Ocorrência de longa data, desde o acesso o acesso às ondas do rádio. Na memória dos entrevistados, podemos recuar a referências até, pelo menos, a década de 1950.

Maria Francisca Santana Albuquerque, de 78 anos, uma das moradoras mais idosas da comunidade, lembra-se de ouvir radionovelas nos anos 1950. Segundo ela, a audiência de radionovelas era basicamente feminina. Maria Francisca sempre se juntava à filha para acompanhar os novos episódios. Já o marido dava importância aos noticiários. De todo modo, a propagação sonora dos programas alcançava a todos na casa.

Uma forte lembrança de Maria Francisca é a da notícia, ouvida pelo rádio, do naufrágio de dois barcos que navegavam em direção à Foz do Cravo. $O$ fato não é lembrado com precisão de data (durante a década de 1980), mas a tristeza do acontecimento é ainda hoje presente, ressaltada por ter o fato ganhado grande repercussão no rádio. $\bigcirc$ naufrágio resultou na morte de 20 pessoas, diz a entrevistada, muitas delas naturais da Foz.

O noticiário do rádio, nesse episódio, ganhou uma importância autoevidente para os moradores da Foz, ao relatar um acontecimento que lhes dizia respeito diretamente. Mas num sentido geral, o critério de valorização do conteúdo da programação de rádio, quando em relação com a vida interiorana, pode ser constatado pelo que permaneceu relevante na memória dos entrevistados quanto à experiência radiofônica.

As radionovelas foram, em geral, mencionadas com destaque pelas mulheres entrevistadas. Principalmente, foram destacadas pequenas brigas familiares com irmãos e maridos quando eles atrapalhavam os momentos de "ouvir a novela". No mais, os demais programas mencionados não foram indicados com audiência específica de gênero ou idade.

Nos anos 1960, o acesso ao rádio de pilha tornou mais versáteis as formas de ouvir rádio em Foz do Cravo: dentro ou fora de casa, no rio ou nos caminhos pelo mato. Filho de Maria Francisca, Antonio Paulino Santana Albuquerque, comerciante de 50 anos, tinha preferência por dois programas ouvidos desde a infância: "A patrulha da cidade" e o "Alô, alô interior". Veiculados pelas principais emissoras paraenses dos anos 1960 e 1970, rádio Marajoara e rádio Clube do Pará, esses dois programas são os campeões nas lembranças e nas preferências dos moradores de Foz do Cravo. As duas atrações se completavam, apresentando um quadro amplo de informações sobre o cotidiano da capital e das localidades interioranas do estado. 
"A patrulha da cidade" foi um noticiário policial criado pela rádio Marajoara em 1965. O programa foi copiado de uma atração da rádio Tupi do Rio de Janeiro e assumiu no Pará o mesmo formato, já que as duas emissoras pertenciam à rede Diários Associados, propriedade de Assis Chateaubriand. A rádio Marajoara foi fundada em Belém, em 1954, por Chateaubriand, como uma extensão de seus empreendimentos de comunicação na região, que no Pará já contava com o jornal A Província do Pará, refundado pela rede em 1947, após 21 anos de inatividade (Vieira; Gonçalves, 2003, p. 131-134).

O perfil dramático do programa era destacado pelos quadros "As notícias do pronto-socorro" e "Os dramas da cidade", que apresentava a agenda diária de problemas típicos de uma cidade grande marcada por agudas desigualdades socioeconômicas. Neste último quadro, em particular, "Os dramas da cidade" era encenado por atores do radioteatro da Marajoara, coisa bastante familiar para os ouvintes da Foz. Por seu turno, os relatos de crimes e de procedimentos policiais eram apresentados com forte dose de improviso pelos locutores, outro fator responsável pelo sucesso da atração, comprovado pelo grande número de cartas recebidas por sua produção (Vieira; Gonçalves, 2003). A atração funcionava, portanto, como um noticiário urbano, apresentando os acontecimentos dramáticos do dia a dia da população de Belém.

Já o programa "Alô, alô interior", apresentado na rádio Guajará, nos anos 1960, se inseria numa linha de atrações voltadas preferencialmente para o público interiorano ("da capital e do interior"). Programas como "O regatão vem ấ" e o "Mensageiro para o interior", criados e transmitidos pela rádio Clube do Pará desde os anos 1950, destacavam aspectos socioculturais (costumes, modo de falar, cenários rurais, música) e informações sobre a vida dos moradores do interior do estado. Tratava-se, portanto, de um filão de programação radiofônica consagrado entre o público local desde meados do século XX.

A rádio Clube, como foi indicado, havia sido a pioneira nesse tipo de atração. A emissora de prefixo PRC-5 foi a primeira estação de rádio criada na Amazônia, no formato de emissora de associados, sustentada pelo pagamento de mensalidades dos sócios, prática corrente à época.

Os fundadores da emissora mantinham laços importantes com a elite política local, como era o caso do bacharel em direito e radioamador Roberto Camelier, do ex-governador do estado Dionísio Ausier Bentes, sócio-fundador da emissora, do telegrafista Eriberto Pio e do jornalista Edgar Proença, que ingressou na sociedade logo após sua criação. ${ }^{10}$

A emissora foi presenteada em 1937, pela prefeitura municipal, com um terreno no Bairro do Jurunas, numa localidade não urbanizada e de difícil acesso. No terreno concedido foi erguida a chamada "Aldeia do rádio", onde foram instalados os transmissores e um estúdio para produção de programas. $O$ complexo foi inaugurado em 1939 e permitiu a realização de radionovelas e apresentações musicais ao vivo com artistas locais.

Em 1954, a PRC-5 inaugurou, com outra doação de terreno público, sua nova sede no edifício Palácio do Rádio, erguido na avenida Quinze de Agosto, centro da cidade. Os donos da emissora transferiram a construção do imóvel para um empresário local que, em troca, cedeu todo o segundo andar (de um prédio de quinze andares) à Clube ( $\bigcirc$ Pará [...]).

10 Sobre a trajetória dos fundadores da rádio Clube do Pará, consulte especialmente o capítulo 1 "Uma proto-história do rádio na Amazônia, 1923-1929", em Oliveira (2011, p. 18-85). 
Segundo Vieira e Gonçalves (2003), o transmissor de ondas tropicais de 5 kilowatts da rádio Clube passou a operar em 1942, alcançando trechos mais distantes do interior do Pará e de outros estados da Amazônia. Programas direcionados ao público interiorano como o "Mensageiro para o interior" tornou mais dinâmica a comunicação entre moradores de municípios distantes entre si. Esse tipo de atração não tinha horário fixo nos anos 1940 e 1950, mas eram programas esperados pelos ouvintes durante todo o dia na expectativa de receber e repassar mensagens. Assim, as emissões de mensagens funcionavam como uma espécie de correio radiofônico. Além disso, as mensagens eram pagas pelos remetentes nas emissoras, segundo o critério de cobrança de telegramas: o preço da mensagem correspondia ao número de palavras enviadas (Vieira; Gonçalves, 2003, p. 55).

$\bigcirc$ jornalista Paulo Roberto Ferreira destaca também a existência, em outros estados da Amazônia e territórios federais, de programas informativos e de envio de mensagens para o interior no mesmo período. Em seu artigo são mencionados particularmente dois programas: "Avisos para o interior", de 1945, da rádio Baré, do Amazonas, voltado para a emissão de mensagens para comunidades ribeirinhas; e o programa "Mensageiros no ar", da rádio Roraima, de 1957, que promovia a comunicação entre a cidade de Boa Vista e as áreas de garimpo espalhadas pelo interior (Ferreira, 2005).

Mas voltemos ao programa "Alô, alô interior", veiculado pela rádio Guajará a partir de 1962. A emissora fora fundada 1958, mas só iniciou suas atividades em 1960, por conta das posições políticas do prefeito de Belém e proprietário da emissora, Lopo de Castro, contrárias ao partido do poder no governo federal, o PSD, de Juscelino Kubitschek (Leal, 2010, p. 78). 0 lançamento de "Alô, alô interior", com o locutor Almir Silva - radialista já famoso no rádio maranhense e conhecido pelo público paraense - pretendia garantir algum espaço à nova emissora entre as mais antigas - Clube e Marajoara (Ferreira, 2005).

sucesso do programa resultou, no entanto, na transferência de Almir Silva para a Marajoara em 1970, junto com o seu "Alô, alô interior". O sucesso da atração estava baseado na irreverência do apresentador, que repetia o nome do programa como um chamado pela atenção do público, o que se tornou uma marca do radialista e da memória sobre ele em Belém até os dias de hoje. A repetição da frase "alôralôrinterior", dita assim sem separação entre as palavras, era sempre seguida da mensagem, já paga pelo remetente, que era transmitida duas vezes. Logo após, o locutor fazia algum comentário irreverente sobre a mensagem, geralmente em torno de elementos da vida interiorana ou de um sentido alternativo e chistoso aventado pelo radialista (Leal, 2010, p. 90).

A marca satírica do programa contribuiu para o sucesso de público, mas também atrapalhou a carreira do radialista. Foi o que ocorreu quando, ao ler uma mensagem enviada ao programa, - "Estamos chegando hoje a Belém. Milico passando mal" - Almir comentou, jocosamente, ser aquela a primeira vez em que ouvia sobre "milico passar mal" (Leal, 2010, p. 90), (Bandeira, 2012). $\bigcirc$ fato se deu em plena ditadura militar. Por isso, ao deixar a emissora, o radialista foi preso.

As complicações de Almir Silva com o regime da época, no entanto, não se limitavam a casos de irreverência como este. Ferreira destaca a preocupação dos militares paraenses da época de que o programa pudesse ser usado para o envio de mensagens cifradas para guerri- 
Iheiros comunistas, supostamente embrenhados pelas matas amazônicas (Ferreira, 2005). A suspeita pouco plausível, não era de todo despropositada no contexto da época, pois a Guerrilha do Araguaia, do início dos anos 1970, era tomada pelos militares brasileiros como um exemplo contundente da "conspiração interna comunista", presumidamente entranhada na Amazônia.

Mas o real interessado nas mensagens, o público das cidades, vilas e localidades do interior do estado, estava atento ao conteúdo dos anúncios e ao pedido no final da locução: "Quem escutar essa mensagem, favor transmiti-la ao destinatário" (Bandeira, 2012). Esse movimento de mensagens pelas ondas do rádio acompanhava o fluxo de pessoas entre o campo e a cidade e compunha um conjunto de informação e entretenimento em que os ouvintes do interior eram os personagens principais. Daí porque na memória dos antigos ouvintes de rádio em Foz do Cravo, permanece forte até hoje a lembrança de velhos programas como "O regatão vem aî" e "Calendário social", da rádio Clube. Este, por exemplo, felicitava os aniversariantes que moravam no interior com mensagens pagas por parentes e amigos.

O lucrativo negócio de correio radiofônico das emissoras de Belém se encaixava nos interesses e necessidades de comunicação do público espalhado pelo estado. Notícias, entretenimento e mensagens compunham um tripé através do qual transitavam representações sobre a cidade e o interior. A cidade dos "dramas" veiculados pela "A patrulha da cidade" podia não ser exatamente a mesma que o agricultor João Costa, de 52 anos, nascido na Foz do Cravo, conheceu na adolescência quando morou em Belém. Mas depois de retornar a seu lugar de origem, após o casamento e o nascimento dos filhos, João Costa, talvez ainda tendo em mente os "dramas" urbanos que o rádio ajudou a divulgar, considera mais difícil criar um filho na cidade.

O interior, emblema generalizante da diversidade de núcleos populacionais amazônicos, estava sempre indicado nas mensagens e na memória dos entrevistados, como o mundo dos rios, dos ribeirinhos e do trabalho agrícola. Cidade e interior estavam na grade de programação de rádio, nas notícias e nas mensagens. $\bigcirc$ trânsito comunicativo entre as duas referências socioespaciais era expresso de forma cabal nos usos que os ouvintes faziam desse veículo.

Exemplo disso é a história do nascimento de um dos filhos de Maria da Paz Oliveira, hoje com 57 anos, moradora de Foz do Cravo. Na viagem a Belém para a realização do parto, nos anos 1970, o marido deixou com ela o dinheiro para o anúncio do nascimento do filho, no programa "Alô, alô interior", após o que retornou para a casa no interior. Assim, seria possível saber a data do nascimento do filho e a hora do retorno da esposa para casa.

O rádio era também usado, diz Valdomiro Borges de Oliveira, de 62 anos, agricultor e morador na comunidade, como despertador para que as famílias se levantassem para o dia de trabalho. Segundo Valdomiro, "o rádio arrebanhava o povo do interior". Quer dizer, a preferência por certos programas, inclusive por aqueles que marcariam o início das atividades diárias, tinha um efeito realmente importante na organização das atividades coletivas. Ou seja, os programas poderiam marcar o momento de ir à roça, de ir pescar, de estar junto em família, de ficar só num tempo de descanso. Maria Luzia Albuquerque, dona de casa de 52 anos, lembra de sempre ouvir, na adolescência, um programa musical à tarde no rádio do pai, que ficava pregado à parede da sala. 
Hábitos individuais estão, nesse caso, integrados a práticas coletivas construídas pelos moradores de Foz em torno do interesse por notícias, novelas, programas musicais, humorísticos e de transmissão de mensagens, todos veiculados pelo meio radiofônico.

\section{Considerações finais - memórias como representações espaciais}

A partir da memória dos entrevistados, vimos que o rádio foi usado como um meio de estabelecer conexões, no trânsito de informações e nas representações do campo e da cidade. Não se trata aqui de avaliar o que houve de positivo ou negativo na introdução do rádio na comunidade. A presença e a intensificação dos meios de comunicação nas fronteiras da sociedade nacional foram e são fenômenos inelutáveis, e sua inserção concorreu para redimensionar as percepções nativas sobre o fluxo e a configuração do espaço regional. Ao mesmo tempo, usos, significados e adaptações atribuídas pelos ouvintes a esses meios nas realidades "interioranas" promoveram reorientações de mecanismos supostamente impessoais da indústria cultural.

O mais importante neste texto é compreender as nuances sociológicas e históricas dessas percepções dos ribeirinhos de Foz do Cravo como realidade "microscópica" que tem muito a dizer sobre as diversas realidades socioespaciais da região. Como na Foz do Cravo, outras comunidades espalhadas pelos "sertões" e "litorais" amazônicos certamente usaram o rádio para superar as distâncias e os obstáculos naturais por meio de trocas comunicativas.

O filtro da memória dos entrevistados destaca o que era e é significativo para os moradores da comunidade sobre o hábito de ouvir rádio. As representações espaciais construídas historicamente na troca comunicativa por meio das ondas radiofônicas são, até hoje, relevantes e atuantes para compreender a organização espacial da região onde se insere a comunidade.

Atualmente, a Foz do Cravo está inserida numa região marcada pela rodovia como polo de atração da atividade produtiva e pela influência de empreendimentos agrícolas de grande porte, ancorados na grande propriedade. Hoje, os moradores vivem ali na era da televisão digital, do telefone celular e da internet. E certamente conta, para o uso desses novos media, o aprendizado histórico e coletivo do uso do rádio como instrumento para manter o modo de vida local. As memórias interioranas aqui levantadas mostram como os conteúdos dos meios de comunicação se difundem sempre em função das realidades sociais específicas e de sua relação com contextos mais amplos.

\section{Referências}

ANTONIO CANDIDO (Antonio Cândido de Mello e Souza). Os parceiros do rio Bonito. São Paulo: José Olympio, 1964.

BANDEIRA, E. C. As ondas e a selva. Textos no Tucupi: um blog amazônico para belenenses, paraenses e brasileiros. Disponível em: <http://tucupi.wordpress.com/2006/01/26/ as_ondas_e_a_selva>. Acesso em: 2 mar. 2012.

CASTRO, E. Quilombos de Bujaru: memória da escravidão, territorialidade e titulação de terra. Belém: Seju/Programa Raízes/Unamaz, 2003. Relatório de Pesquisa. 
CHAMBOULEYRON, R. Povoamento, ocupação e agricultura na Amazônia colonial (16401706). Belém: Açaí/PPHIST/CMA, 2010.

CHARTIER, R. A história cultural: entre práticas e representações. Rio de Janeiro: Bertrand Brasil, 1990.

DURHAM, E. A caminho da cidade: a vida rural e a migração para São Paulo. São Paulo: Perspectiva, 1978.

FERREIRA, P. R. Após o regatão, o rádio e a televisão. In: ENCONTRO NACIONAL DA REDE ALFREDO DE CARVALHO, 3., 2005, Novo Hamburgo. Anais... Novo Hamburgo: Alcar, 2005. Disponível em: <http://paginas.ufrgs.br/alcar/encontros-nacionais-1/3o-encontro-2005-1>. Acesso em: 2 mar. 2012.

HALBWACHS, M. A memória coletiva. São Paulo: Centauro, 2006.

HARRIS, M. Town and Country in Brazil. New York: Columbia University Press, 1956.

LEAL, E. Rádio Repórter: o microfone aberto do passado. Belém: Meta Editorial, 2010.

MACEDO, C. O. Territorialidade camponesa na comunidade do Cravo nordeste do Pará. In: FARES, J. A. et al. (Org.). Sociedade e saberes na Amazônia. Belém: Eduepa, 2011.

OLIVEIRA, E. V. B. Modernidade e integração na Amazônia: intelligentsia e broadcasting no entre guerras, 1923-1937. Dissertação (Mestrado em História Social da Amazônia) Universidade Federal do Pará, Belém, 2011.

O PARÁ NAS ONDAS DO RÁDIO. Disponível em: <www.oparanasondasdoradio.ufpa. br $\geq$. Acesso em: 5 maio 2010.

PORTELli, A. O massacre de Civitella Val di Chiana (Toscana, 29 de junho de 1944): mito e política, luto e senso comum. In: AMADO, J.; FERREIRA, M. M. (Org.). Usos e Abusos da História Oral. Rio de Janeiro: FGV, 2006.

ROCHA, A. Nas ondas da modernização: o rádio e a TV no Brasil de 1950 a 1970. Rio de Janeiro: Aeroplano/Faperj, 2007.

TINHORÃO, J. R. Música popular: do gramofone ao rádio e TV. São Paulo: Ática, 1981.

TRINDADE JR., S.-C. C. Entre o público e o privado: agentes e estratégias de apropriação do espaço na orla fluvial de Belém-Pará (Brasil). Scripta Nova, Barcelona, v. IX, n. 194, p. 194-199, 2005.

VIEIRA, R.; GONÇALVES, F. Ligo o rádio pra sonhar: a história do rádio no Pará. Belém: Prefeitura Municipal de Belém, 2003.

WAGLEY, C. Uma comunidade Amazônica. São Paulo: Editora Nacional, 1957.

WILLEMS, E. Uma vila brasileira: tradição e transição. São Paulo: Difusão Europeia do Livro, 1961.

WILLEMS, E.; MUSSOLINI, G. Buzios Island: a caiçara community in Southern Brazil. New York: Louis Valley, 1952. 